Perspective

\title{
Recent progress on core-shell nanocatalysts
}

\author{
Qiang Sun, Xiang-Qian Zhang, Yang Wang, An-Hui Lu*
}

\section{Introduction}

During the past few decades, there have been comprehensive studies on nanocatalysts with many innovative advances in the precise manipulation of their structure and morphology on a nanometer scale by both chemists and material scientists [1]. In comparison to bulk catalysts, nanocatalysts have a high surface-to-volume ratio due to the small particles and have a large fraction of active atoms with dangling bonds exposed on the surface, which can give rise to a significant increase in catalytic activity [2,3]. The core-shell nanoparticle structure, with an inner core encapsulated by an outer shell, is considered a good platform for the fabrication of high performance nanocatalysts [4-10]. Core-shell nanocatalysts not only can improve the catalytic performance, but also can effectively prevent the migration and aggregation of the nanoscale active sites due to the protective shell. Hence, the design and synthesis of multifunctional nanocatalysts on the basis of a core-shell structure can create new opportunities for their applications in heterogeneous catalysis [11-15].

We summarize the recent progress on the design and fabrication of multifunctional core-shell nanocatalysts (Fig. 1), mainly discussing synthesis principles and catalytic performance. We first summarize the state-of-the art progress in the strategies for preparing hollow core-shell nanoparticles (the core diameter is smaller than the inner diameter of the shell) with different shapes, compositions, and mobile (single or multiple) cores. Then, magnetic core-shell nanocatalysts, where a magnetic nanoparticle is the core material, are introduced that use shell materials such as silica, carbon and polymers. Then, a series of very compact multifunctional core-shell nanoreactors for tandem reactions are discussed in terms of the activity, selectivity and stability of a one-pot catalytic process. Finally, we review the challenges and future developments in multifunctional core-shell structured nanocatalysts. We believe that the continuous study of such engineered multifunctional core-shell structures will facilitate a deep understanding of the correlation between the catalyst structure and performance. In turn, the knowledge gained will guide us in the precise preparation of high performance catalysts for increasing product yield and saving operation time and resources.

\section{A hollow core-shell nanostructure as a platform for the fabrication of a nanocatalyst}

The hollow core-shell nanostructure, i.e., yolk-shell or nanorattle, is a special class of core-shell structure with a distinctive core@void@shell configuration. It has generated a great deal of interest due to its complex hierarchical nanostructure and intriguing properties, such as low density, high surface area, and interstitial hollow spaces. When used as a nanocatalyst, a hollow core-shell nanostructure with a metal core (e.g., $\mathrm{Au}, \mathrm{Ag}, \mathrm{Pt}, \mathrm{Ni}$ ) is among the most important catalysts with a high catalytic activity for several important heterogeneous catalysis reactions. The shell plays an important function in the preservation of the composition and structural integrity of the entire catalyst, and prevents the core from aggregating or sintering to large particles. The porosity of the shell and chemical composition of the shell surface can also be tuned to selectively control the diffusion of molecules into and out of the in-

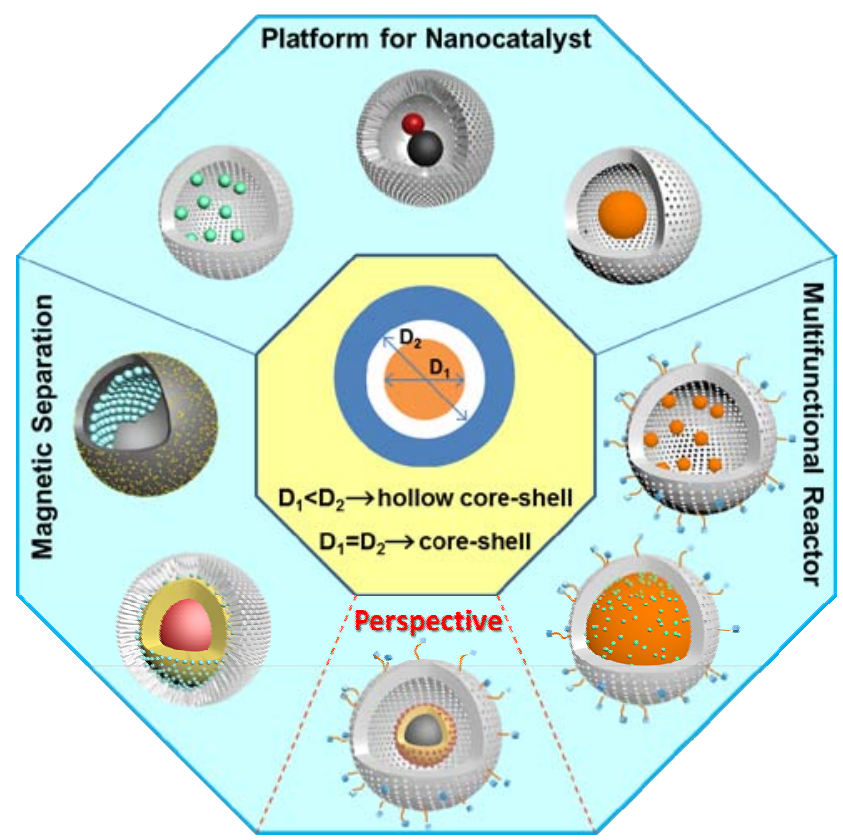

Fig. 1. Illustration of core-shell nanocatalysts with different structures. 
terior cavity to increase the solubility and/or biocompatibility of the overall nanostructure, and to add new physical or chemical properties [16-18].

Among the various approaches, the selective etching method pioneered by Xia's group [19] has been widely used for the synthesis of the novel Au@poly(benzyl methacrylate) (PBzMA) hollow core-shell nanostructure. This hollow core-shell nanostructure represents a unique system for the diffusion of chemicals through the shell. Following this work, significant development has been made in the preparation of catalysts with this structure including $\mathrm{Au} @ \mathrm{TiO}_{2}$ [20,21], $\mathrm{Au} @ \mathrm{ZrO}_{2}$ [22-25], Pd@ $\mathrm{CeO}_{2}$ [26], and Pt@TiO2 [27]. As an example, the $\mathrm{Au} @ \mathrm{SiO}_{2}$ hollow core-shell nanostructure (Fig. 2) was synthesized by the selective etching of the gold core by KCN [28], when $\mathrm{Au@SiO} 2$ core-shell nanoparticles were first synthesized using the classical Stöber method. As shown in Fig. 2(a), a silica shell is evenly coated on a spherical core with an average gold core size of $120 \pm 10 \mathrm{~nm}$ and $\mathrm{SiO}_{2}$ shell thickness of $32 \pm 2 \mathrm{~nm}$. More importantly, by repeating the $\mathrm{KCN}$ treatment, the average size of the gold cores were reduced without damaging the silica shells. When the gold core was etched, its surface became rougher with sharp edges and facets because of the different activities of the different crystal facets. When using the $\mathrm{Au} @ \mathrm{SiO}_{2}$ hollow core-shell nanoparticles as a catalyst for the reduction of $p$-nitrophenol by $\mathrm{NaBH}_{4}$, the resulting reaction rate constant was decreased from $1.4 \times 10^{-2}$ to $3.9 \times 10^{-3} \mathrm{~s}^{-1}$ as the core diameter was reduced from 104 to $43 \mathrm{~nm}$ (Fig. 2(c)). The TOF was increased five times from 6.6 to $36 \mathrm{~s}^{-1}$ when the core diameter was reduced from 104 to $43 \mathrm{~nm}$. That was due to the decrease of the particle size leading to the increase in low coordination metal sites such as vertices, edges and kinks, which result in the effective adsorption of the reactants and facilitating the reaction rate. In addition, the porosity of the $\mathrm{SiO}_{2}$ shell can be tuned by using long alkyl chain siloxanes such as $\mathrm{C}_{18} \mathrm{TMS}$ (octadecyltrimethoxysilane). The surface of the Au nanoparticles core can be functionalized using a terminal carboxylic acid ligand such as 3-mercaptopropionic acid [29].

Using a similar acid etching treatment, $\mathrm{Ni@SiO} 2$ hollow core-shell nanocatalysts were also synthesized by partial etching of the nickel cores [30,31]. Adjustment of the hydrochloric acid concentration allowed nickel cores with different diameters to be obtained. Due to the protection of the
$\mathrm{SiO}_{2}$ shell, the $\mathrm{Ni@SiO} 2$ retained its hollow core-shell morphology without $\mathrm{Ni}$ agglomeration even after a high temperature treatment at $500{ }^{\circ} \mathrm{C}$ for $2 \mathrm{~h}$ under a $\mathrm{H}_{2}$ atmosphere. When used for steam methane reforming reactions, the $\mathrm{Ni@SiO} 2$ nanocatalyst showed a remarkably improved activity over the commercial catalysts, with excellent stability. This indicates that the rational design of the catalyst is a powerful way to improve the catalytic performance in terms of activity, thermal stability, and recyclability.

A hard-templating method has also been used as a general and effective strategy for the synthesis of hollow core-shell nanocatalysts because of the mechanical stability of the hard template. The synthesis procedure includes the following three steps: noble metal nanoparticles are first coated with a layer of solid material to form a core-shell nanostructure, a shell material is deposited onto the surface of the solid material to form a sandwich nanostructure, which is followed by selective removal of the solid material layer using liquid dissolution or gas phase calcination [32].

Using this strategy, Schüth and co-workers [33-35] first made a core-shell $\mathrm{Au} @ \mathrm{SiO}_{2}$ nanostructure and then they selectively etched part of the Au core by $\mathrm{KCN}$ to reduce the particle size. Then, they continued to coat another $\mathrm{ZrO}_{2}$ shell onto the $\mathrm{SiO}_{2}$ surface, and finally the $\mathrm{Au@ \textrm {ZrO } _ { 2 }}$ hollow core-shell nanostructure was obtained by removing the intermediate $\mathrm{SiO}_{2}$ template. The authors investigated the catalytic activity of a Au@ZrO2 yolk-shell nanostructure with a 14 nm gold core for CO oxidation and compared this with a Au@C yolk-shell nanostructure of the same core size. The activity of the carbon-based catalyst was at least one order of magnitude lower than that of $\mathrm{ZrO}_{2}$. Stucky et al. [36] have reported an assembly route to prepare a hollow core-shell catalytic nanoreactor with a $6.3 \mathrm{~nm}$ gold nanoparticle core and a mesoporous $\mathrm{ZrO}_{2}$ or $\mathrm{TiO}_{2}$ shell starting from monodisperse hydrophobic $\mathrm{Au}$ nanoparticles. When used for catalytic CO oxidation, the $\mathrm{Au} @ \mathrm{TiO}_{2}$ hollow core-shell nanostructure exhibited good performance, especially after calcination at $300{ }^{\circ} \mathrm{C}$, which revealed an improved synergetic effect between the gold core and the porous $\mathrm{TiO}_{2}$ shell.

Besides the hollow core-shell nanostructure with a single metal core, multi-core metal-based yolk-shell nanocatalysts have also been developed. Song's group [37,38] succeeded in growing several Pd nanoparticles inside a mesoporous silica
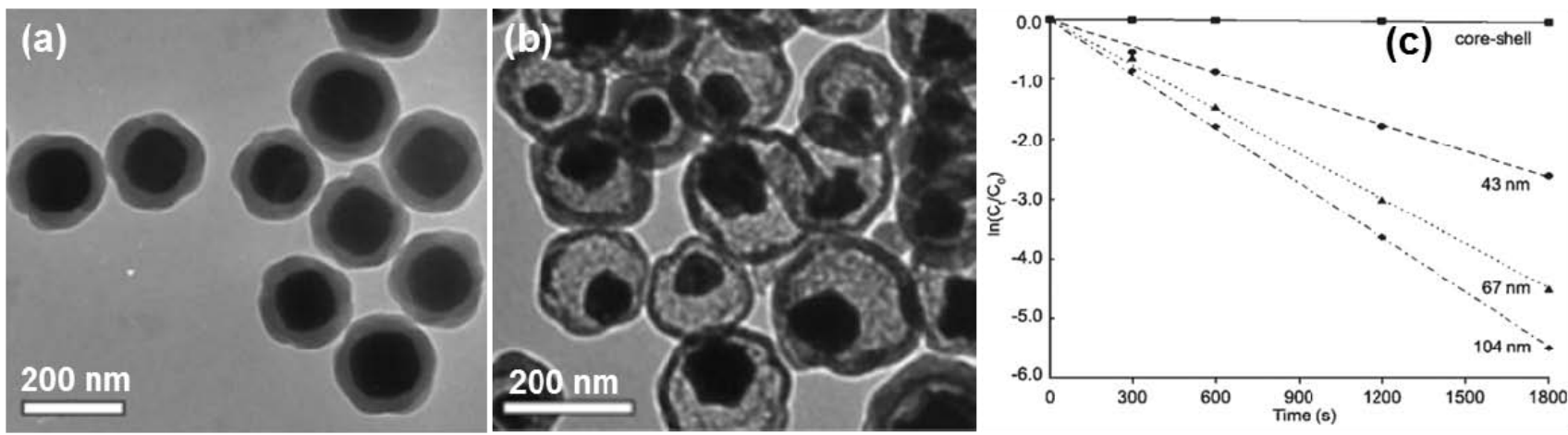

Fig. 2. TEM images of (a) $\mathrm{Au} @ \mathrm{SiO}_{2}$ core-shell nanostructures; (b) $\mathrm{Au} @ \mathrm{SiO}_{2}$ hollow core-shell nanocatalysts; (c) Plot of $\ln \left(\mathrm{C}_{t} / \mathrm{C}_{0}\right)$ versus time for these hollow core-shell nanocatalysts [28]. 
sphere as a yolk-shell nanoreactor, which gave a high activity of 99.5\% yield in 3 min for Suzuki cross-coupling reactions. In addition, multiple gold nanoparticles were also entrapped by a poly(styrene-co-methylacrylic acid) shell. With this nanoreactor as the catalyst for aerobic alcohol oxidation to form the acid, the reaction was completed in $30-120 \mathrm{~min}$, and had a TOF ranging from 100 to $400 \mathrm{~h}^{-1}$.

In addition to the above approaches, Tang and co-workers [39] synthesized a silica yolk-shell nanocatalyst with a gold nanoparticle confined inside the hollow void using an impregnation method (Fig. 3). The Au particle size was varied by changing the concentration of the $\mathrm{HAuCl}_{4}$. This type of hollow core-shell nanocatalyst showed high catalytic performance in the reduction of 2-nitroaniline to produce phenylenediamine. Yang's group [40,41] confined the solid acid-based core (polystyrene sulphonic acid resins) inside a hollow silica nanosphere. The hybrid yolk-shell solid acid catalyst demonstrated high activity and selectivity in a series of important acid-catalyzed reactions, which can be an efficient strategy to fabricate hybrid solid acid catalysts for green chemical processes. Bao's group [42] have encapsulated metallic Fe nanoparticles into the compartments of pea pod-like carbon nanotubes. Due to the protection of the carbon nanotubes, the direct contact of the metal particles with the harsh environment, including the acid medium, and oxygen and sulfur contamination, was avoided. More importantly, the protection tubes did not impede the activation of $\mathrm{O}_{2}$ and the catalyst had high activity and long term stability in ORR even in the presence of $\mathrm{SO}_{2}$ poison.

It is very impressive that both the mobile core and hollow shell in the yolk-shell nanostructure are easily tailored and functionalized to generate novel properties, and the enclosed void space of the yolk-shell nanostructure can be used for the confinement of more reactants with access to the active sites. However, although much advance has been made, the study of hollow core-shell nanostructures is still in its infancy. To meet the requirements of practical applications, hollow core-shell nanocatalysts with more complex structures and new components of the core and shell are still desired.
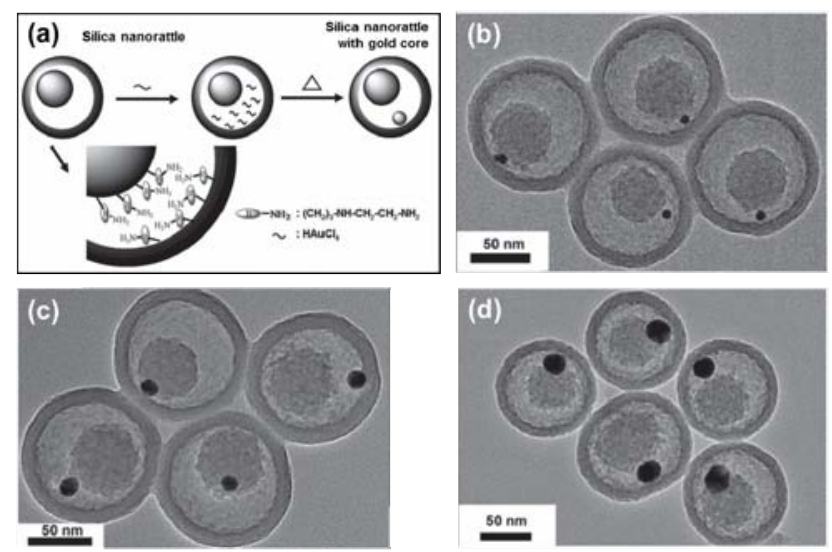

Fig. 3. (a) Schematic of the preparation of a gold core in silica nanorattle; (b)-(d) TEM images of the silica hollow core-shell nanocatalyst with a Au nanoparticle synthesized with the $\mathrm{HAuCl}_{4}$ concentrations of $0.025 \mathrm{~mol} / \mathrm{L}, 0.05 \mathrm{~mol} / \mathrm{L}$, and $0.2 \mathrm{~mol} / \mathrm{L}$ [39].

\section{Magnetic core-shell nanocatalysts for facile separation}

Nanocatalysts are considered a bridge between homogeneous and heterogeneous catalysts $[43,44]$. In general, they show high catalytic activity and selectivity. Nevertheless, a remaining issue is to have an effective separation and recovery of the nanocatalysts [45]. To do this, the fabrication of a magnetic nanocatalyst would allow easy recovery with an external magnet. To date, many magnetic nanocatalysts have been synthesized by the entrapment of the noble metal and grafting ligands onto the surface of the magnetic support, or by embedding active components in a magnetic composite [46-48]. To successfully apply the magnetic nanocatalyst, it should have the properties of long term magnetic stability, and high activity and selectivity.

Recently, magnetic materials with a core-shell structure have been investigated as magnetically recyclable catalysts for heterogeneous reactions [49-52], in which the shell consists of the catalytically active species and the magnetic core acts as the anchor to separate and recycle the catalyst [53-55]. One mature methodology is to coat the previously synthesized cores with silica. For example, Salgueiriño-Maceira and coworkers [56] reported the synthesis of iron oxide nanoparticles coated with a silica shell that were subsequently functionalized with gold nanoparticles. Bedford et al. [57] demonstrated that iron nanoparticles stabilized by 1,6-bis(diphenylphosphino)hexane or polyethylene glycol exhibit high activity for the cross-coupling of aryl Grignard reagents with primary and secondary alkyl halides bearing $\beta$-H atoms. This catalyst was proven effective in a tandem ring-closing/cross-coupling reaction.

Yin's group [58-62] have made substantial contribution in developing recoverable nanocatalysts with a core-shell structure that much improved the stability of the catalytic nanoparticles using a general "encapsulation and etching" strategy. To increase the loading and have magnetic separation of the catalytic nanoparticles, they developed a core-satellite nanocatalyst system with a sol-gel process [63]. As shown in Fig. 4(a), a

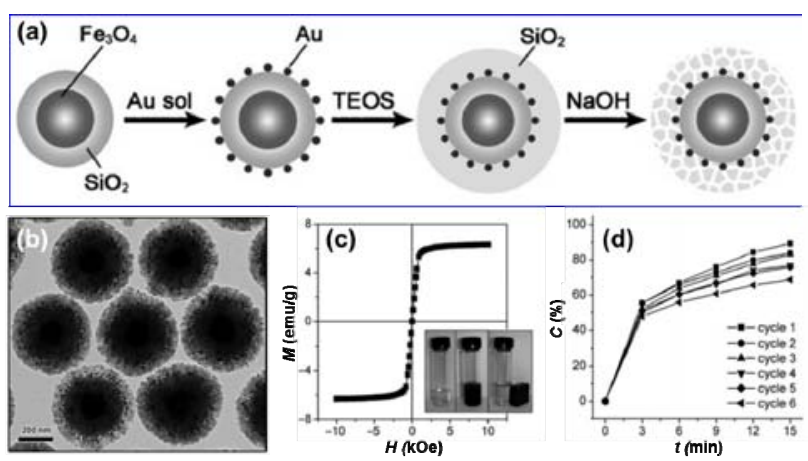

Fig. 4. Synthesis procedure (a) and typical TEM image (b) of a porous silica protected $\mathrm{Fe}_{3} \mathrm{O}_{4} / \mathrm{SiO}_{2} / \mathrm{Au}$ composite structure. (c) Magnetization $M$ as a function of applied external field $\mathrm{H}$ for a typical composite catalyst at room temperature. The photos in the inset demonstrated the convenient separation of the catalyst using an external magnet. (d) Plot of the conversion $C$ of 4-NP as a function of reaction time $t$ in six successive cycles of reduction and magnetic recycling using the $\mathrm{Fe}_{3} \mathrm{O}_{4} / \mathrm{SiO}_{2} / \mathrm{Au}$ core-shell composite catalyst [62]. 
core-shell $\mathrm{Fe}_{3} \mathrm{O}_{4} / \mathrm{SiO}_{2}$ was first fabricated. Afterwards, a monolayer of gold was immobilized on the surface of the silica colloid using a coupling agent. The core-shell structure was then coated with another layer of silica to the desired thickness to fix the position of the gold nanoparticles. Finally, a "surface-protected etching" technique was applied to make the outer shell mesoporous, and the average pore size increased by etching. Gold nanoparticles were sandwiched between the solid silica core and porous silica shell. This configuration allowed the gold particles to remain stable against coagulation and they were accessible to the reacting species outside the shell (Fig. 4(b)). In the liquid phase reduction of 4-nitrophenol (4-NP), both the rate constant and TOF showed a higher catalytic efficiency for the Au nanocatalyst confined in a silica shell with large mesopores. The enhanced diffusion of reactants in the large pores was responsible for the increased catalytic efficiency. Furthermore, the catalyst can be collected by a magnet for reuse and good activity was maintained over six recycles (Fig. 4(c) and (d)).

Distinct from the "encapsulation and etching" strategy, Lu and co-workers [64] synthesized a core-shell catalyst stable at high temperature for ammonia decomposition by the base-catalyzed hydrolysis of tetraethyl-orthosilicate with cetyltetra-methylammonium bromide ( $\mathrm{CTABr}$ ) as a porogen. A highly active catalyst was fabricated based on $\alpha-\mathrm{Fe}_{2} \mathrm{O}_{3}$ nanoparticles coated by a porous silica shell by a bottom-up approach. The catalysts show high activity, particularly above 600 ${ }^{\circ} \mathrm{C}$, while maintaining stability up to $800{ }^{\circ} \mathrm{C}$. No diffusion limitation was detected, which was possibly due to the porous silica shell. No visible agglomeration occurred in the core-shell catalyst during catalytic tests up to $800{ }^{\circ} \mathrm{C}$. All the iron-based particles were still centered within the unchanged porous $\mathrm{SiO}_{2}$ shell. Due to the shell protection, the catalyst was very stable at 750 ${ }^{\circ} \mathrm{C}$ and maintained a conversion of $80 \%$ for the testing period time of $33 \mathrm{~h}$.

Zhao's group [65] reported a novel multicomponent and

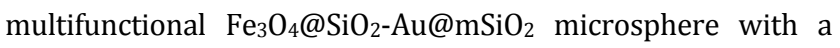
well-defined core-shell-shell nanostructure. They made the confined catalytic gold nanoparticles and accessible ordered mesopore channels by combining a sol-gel process, interfacial deposition, and surfactant-templating approach. The designed microsphere, with a magnetization of $18.6 \mathrm{emu} / \mathrm{g}$ and highly open and ordered mesopores centered at $2.2 \mathrm{~nm}$, contained protected but accessible gold nanoparticles. The multifunctional microspheres catalyzed reduction of 4-NP with a high catalytic activity of $95 \%$ conversion at room temperature and had a highly selective epoxidation of styrene with a selectivity higher than $80 \%$ at $82{ }^{\circ} \mathrm{C}$ (Fig. 5). As a result of the high magnetite content, the $\mathrm{Fe}_{3} \mathrm{O}_{4} @ \mathrm{SiO}_{2}-\mathrm{Au} @ \mathrm{mSiO}_{2}$ microspheres can be readily separated from its solution in less than $1 \mathrm{~min}$ by simply using a magnet. No significant decrease in conversion or selectivity was observed after recycling for more than 7 times.

Several research groups have demonstrated the synthesis of various magnetic silica-coated nanostructures [66-69]. Notably, Moon and Hyeon [66] synthesized $\mathrm{Fe}_{3} \mathrm{O}_{4} @ \mathrm{mSiO}_{2}$ particles with tunable diameters of $45,60,90$, and $105 \mathrm{~nm}$ by varying the concentration of the core nanocrystal during the formation
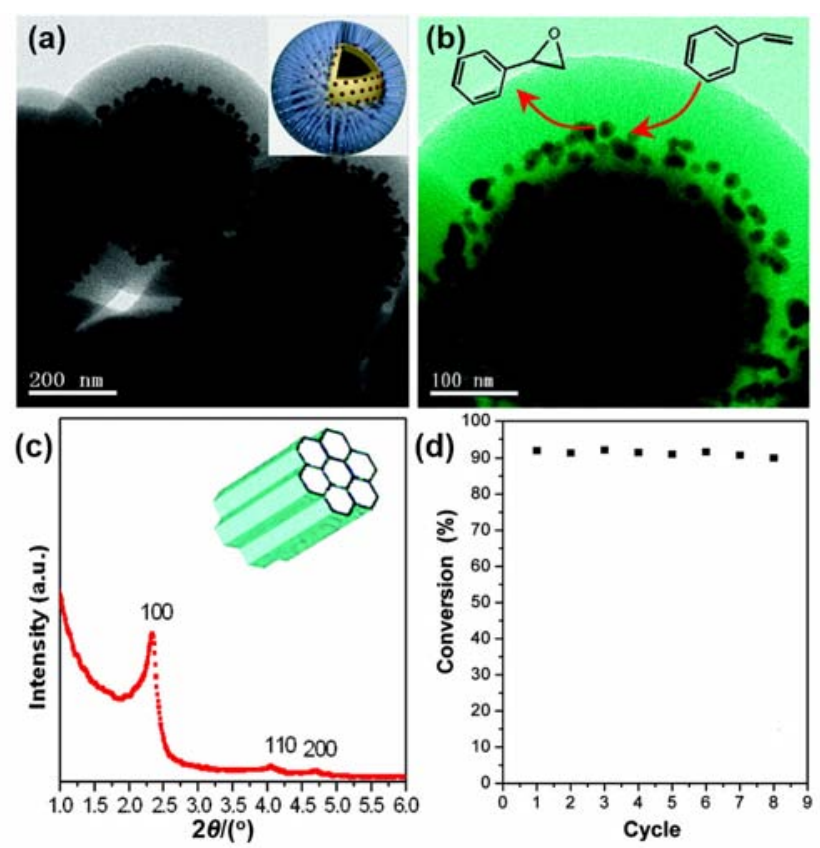

Fig. 5. (a) and (b) TEM images, (c) low-angle XRD pattern and (d) catalyst reusability of the $\mathrm{Fe}_{3} \mathrm{O}_{4} @ \mathrm{SiO}_{2}-\mathrm{Au} @ \mathrm{mSiO}_{2}$ microspheres for the reduction of 4-nitrophenol with $\mathrm{NaBH}_{4}$ [65].

of the mesoporous silica shell. Lee and coworkers [67] demonstrated the utility of nanorattles as nanoreactors to template the growth of nanocrystals inside the cavity, such as $\mathrm{Fe}_{3} \mathrm{O}_{4} / \mathrm{Au} @ \mathrm{SiO}_{2}$. A magnetic core-shell nanohybrid, $\mathrm{Fe}_{3} \mathrm{O}_{4} @ \mathrm{SiO}_{2} @ \mathrm{Pd}-\mathrm{Au}$, was synthesized by reducing palladium and gold cations previously bonded to the amine ligand-modified surface of silica-encapsulated $\mathrm{Fe}_{3} \mathrm{O}_{4}$ nanoparticles. This served as an efficient and recyclable catalyst for the liquid phase hydrodechlorination of 4-chlorophenol under mild conditions [68].

The large scale and easy synthesis of colloidal core-shell and other hybrid nanoparticles by solution chemistry approaches has been pursued by chemists. Lu's group [70] demonstrated a facile and controllable synthesis route for the fabrication of a mushroom nanostructure ( $\mathrm{Fe}_{x} \mathrm{O}_{y} @ \mathrm{PSD}-\mathrm{SiO}_{2}$ ) and its hollow derivatives. The synthesis consists of the partial coating of $\mathrm{Fe}_{x} \mathrm{O}_{y}\left(\mathrm{Fe}_{3} \mathrm{O}_{4}\right.$ or $\left.\mathrm{Fe}_{2} \mathrm{O}_{3}\right)$ with a polymer sphere, followed by attaching a silica hemisphere (Fig. 6). The surface and accessible $\mathrm{Fe}_{x} \mathrm{O}_{y}$ nanoparticles on the Janus-type $\mathrm{Fe}_{x} \mathrm{O}_{y} @ P S D$ nanospheres were the key for directing the growth of the silica hemisphere on the $\mathrm{Fe}_{x} \mathrm{O}_{y} @ \mathrm{PSD}$ seeds. The size and porosity of the silica hemispheres were tunable by adjusting the amount of TEOS used and addition of a proper surfactant via a Stöber process. After the iron oxide cores were leached out with concentrated hydrochloric acid, a mushroom nanostructure with a hollow interior was obtained. The morphology of the hollow interior faithfully replicated the shape of the iron oxide core previously filling this void. This synthesis strategy provides a controllable method for the large scale preparation of an asymmetric colloidal nanostructure, which can be the building block for the assembly of new types of nanostructures.

In contrast to porous silicas, porous carbon and especially a hollow carbon nanostructure are considered promising candi- 


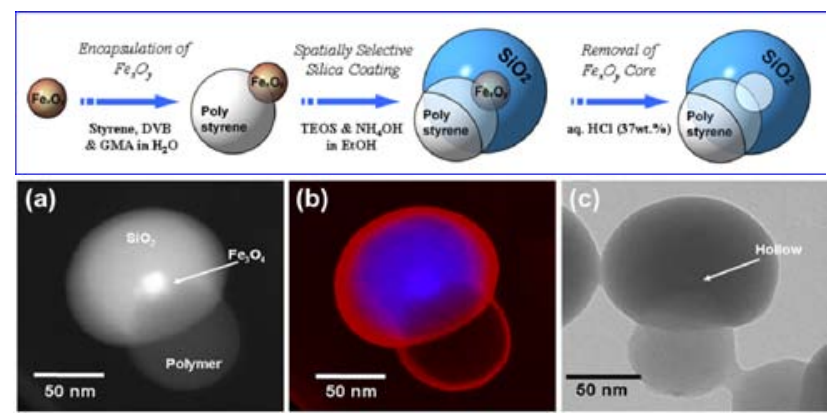

Fig. 6. Synthesis procedure for the mushroom nanostructure (top); Dark field STEM image (a) and SEM and dark field STEM overlapping image (b) of $\mathrm{Fe}_{3} \mathrm{O}_{4} @ \mathrm{DVB}-2-\mathrm{SiO}_{2}$ nanoparticles and TEM image (c) of $\mathrm{Fe}_{3} \mathrm{O}_{4} @$ DVB-2-SiO ${ }_{2}$ nanoparticles after $\mathrm{HCl}$ leaching [70].

dates as a catalyst support due to the large fraction of void space in the hollow structure, low effective density and high specific surface area [71]. Lu and co-workers developed a new and facile method for the fabrication of a bifunctional magnetic yolk-shell type nanocatalyst [72] by the direct encapsulation of magnetic $\mathrm{Fe}_{3} \mathrm{O}_{4}$ nanoparticles within the hollow core and inlaying Pt nanoparticles (other noble metals, Pd and Ag, are also possible) in the carbon shell (Fig. 7(a)). The SEM image in Fig. 7(b) shows a cut hemisphere of $\mathrm{Fe}_{3} \mathrm{O}_{4} @$ @- $\mathrm{C} / \mathrm{Pt}$. One can observe that the $\mathrm{Fe}_{3} \mathrm{O}_{4}$ nanoparticles were in all cases nicely encapsulated within the hollow structure, and Pt nanoparticles were embedded on the outer surface of $\mathrm{Fe}_{3} \mathrm{O}_{4} @ h-\mathrm{C} / \mathrm{Pt}$. This allowed reactants easy access to the surface-located Pt active sites. The same method can be used to fabricate Pd and Ag nanoparticles supported on a bifunctional yolk-shell nanosphere. The magnetic nanocatalyst was collected by a magnet for reuse, and gave $99 \%$ yield of aniline over seven consecutive runs without deactivation (Fig. 7(c)).

It is widely accepted that a solid acid catalyst is preferable to a liquid acid (e.g., $\mathrm{H}_{2} \mathrm{SO}_{4}, \mathrm{HF}$, and $\mathrm{H}_{3} \mathrm{PO}_{4}$ ). The latter can cause difficulties in product separation, equipment corrosion, and environmental pollution. Core-shell catalysts using a polymeric shell is interesting since they can be synthesized with a broad range of incorporated functionalities, such as sulfonic acid groups [73]. Using this strategy, Lu et al provided a simple and reproducible method for the preparation of 16-heptadecenoic
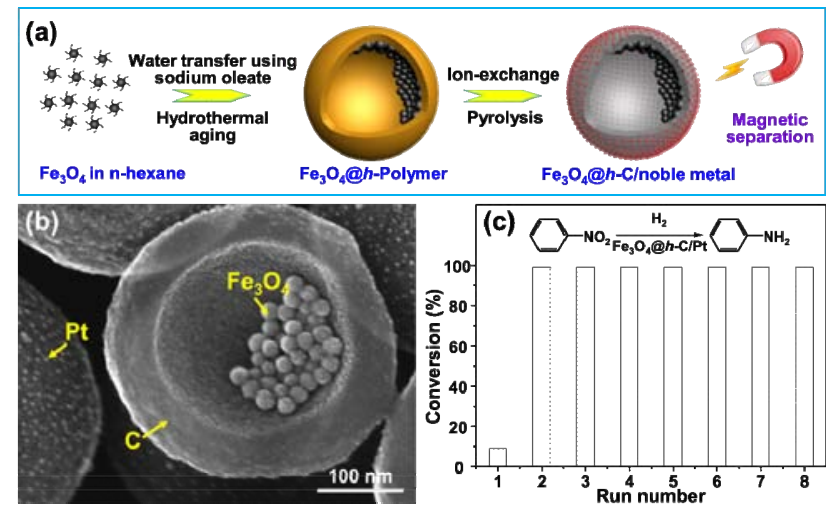

Fig. 7. (a) Schematic of the synthesis procedure for a $\mathrm{Fe}_{3} \mathrm{O}_{4} @ h-\mathrm{C} /$ noble metal; (b) SEM image of $\mathrm{Fe}_{3} \mathrm{O}_{4} @ h$-C/Pd after cutting the hollow carbon spheres into hemispheres; (c) Conversion by the recycled $\mathrm{Fe}_{3} \mathrm{O}_{4} @ h-\mathrm{C} / \mathrm{Pt}$ catalyst for the hydrogenation of nitrobenzene [72]. acid-functionalized magnetite nanoparticles, namely, poly(styrene-co-divinylbenzene) encapsulated $\mathrm{Fe}_{3} \mathrm{O}_{4}$ nanoparticles. This magnetically recyclable catalyst has $\mathrm{H}^{+}$content in the range of $2.2-2.5 \mathrm{mmol} / \mathrm{g}$ and surface area of $45-120 \mathrm{~m}^{2} / \mathrm{g}$. When used for the condensation reaction of benzaldehyde and ethylene glycol, it showed high activity, high selectivity and long term stability. This catalyst exhibited its unique properties by combining the advantages of high surface area, colloidal dispersibility in a polar solvent, magnetic separability, and long term stability.

Magnetic separation makes the recovery of the catalyst in a liquid phase reaction much easier than by cross-flow filtration or centrifugation, especially when the catalyst is in the sub-micrometer or nanometer size range. These core-shell structured and magnetically separable catalysts combine the advantages of high dispersion and activity with easy separation. The synthesized hybrid catalysts are expected to find use in many important industrial applications where separation and recycling are required to reduce the cost as well as waste production.

\section{Multifunctional core-shell nanocatalysts for one-pot tandem reactions}

In general, for a multiple step reaction, a tedious separation procedure for the reactants and products is needed. This consumes large amounts of energy and solvent, and consequently generate considerable amounts of waste, cause high operation costs and severe environmental pollution. Hence, a rationally designed multifunctional catalyst suitable for a tandem or cascade reaction is the key to simplify the synthesis procedure and reduce the amount of waste and lower the operation cost [74-76].

Much attention has been directed to exploit a multifunctional nanostructure that integrates two or more primary functions in one single catalyst, namely, a tandem catalyst. Such a catalyst must adapt to the reaction conditions and exhibit good compatibility with the reactants, which are the major hurdles to overcome [77-80]. To efficiently catalyze a tandem reaction, a nanocatalyst with a precisely integrated functionality and spatially-controlled location of the active sites are required [81-85]. A core-shell configuration, which allows researchers to independently tune the properties of the core and the shell, such as composition, functionality, and thermal stability, has exhibited significant potential in the rational design of tandem catalysts [86-95]. Significantly, each functional core in the core-shell structure is isolated by a permeable shell and has a homogeneous environment, thus sintering of functional cores can be effectively hindered even under harsh conditions [96-99]. In this section, the recent progress on the synthesis of core-shell based tandem nanocatalysts is discussed.

$\mathrm{Wu}$ and co-authors [100] have synthesized a novel coreshell structured composite material TS-1@mesocarbon with a mesoporous shell and TS-1 titanosilicate as the core by a nanocasting and selective silica etching strategy. The replica structure was constructed from the hybrid of TS-1@mesosilica and carbon when tetrapropylammonium hydroxide (TPAOH) 
was employed to selectively remove the amorphous mesosilica shell, while the core zeolite crystal structure was not destroyed. Infiltration of Pd nanoparticles into the mesocarbon shell leads to a novel tandem catalyst with bifunctional catalytic properties, i.e., in situ formation of $\mathrm{H}_{2} \mathrm{O}_{2}$ and subsequent epoxidation of alkene. The Pd/TS-1@MC catalyst was more active for the direct epoxidation of propylene with $\mathrm{H}_{2}$ and $\mathrm{O}_{2}$ compared to the Pd/TS-1 or hydrophilic TS-1@mesosilica as well as a physical mixture of a commercial Pd/C catalyst and TS-1. In addition, they synthesized a centered radially fibrous silica encapsulated TS-1 zeolite (TS-1@KCC-1) in a microemulsion system. After the introduction of $\mathrm{Rh}(\mathrm{OH})_{3}$ species, this novel core-shell structured material served as a robust tandem catalyst for the one-pot synthesis of benzamide from benzaldehyde, ammonia and hydrogen peroxide, in which aldehyde ammoximation and oxime rearrangement occurred in a tandem fashion [101]. This synthesis strategy is versatile and applicable to construct core-shell materials with either mesoporous carbon or silica as the shell and desired zeolites such as NaY, ZSM-5 and beta, as the core.

Recently, Zheng's group prepared hollow mesoporous aluminosilica spheres with pore channels perpendicular to the surface by combining the alkaline etching of solid silica spheres and co-assembly of cationic surfactants, silicate, and aluminate species on the external surface of the solid silica spheres (Fig. 8) [102]. As the mesoporous aluminosilica shells serves as an acid catalyst and the introduced Pd species as catalytic hydrogenation sites, the fabricated Pd/Au@[Na]-HMAS catalysts can be used for one-pot two-step synthesis of 2-(4-aminophenyl)1H-benzimidazole from 4-nitrobenzaldehyde and 1,2-phenylenediamine (Fig. 8(a)). Nearly $100 \%$ conversion of the reactant 4-nitrobenzaldehyde and $92 \%$ yield of 2-(4-aminophenyl)-1H-benzimidazole was achieved (Fig. 8(c)), more than anything previously reported [101,103].

For a multifunctional catalyst to work efficiently, different or even incompatible active sites, such as acidic sites and basic

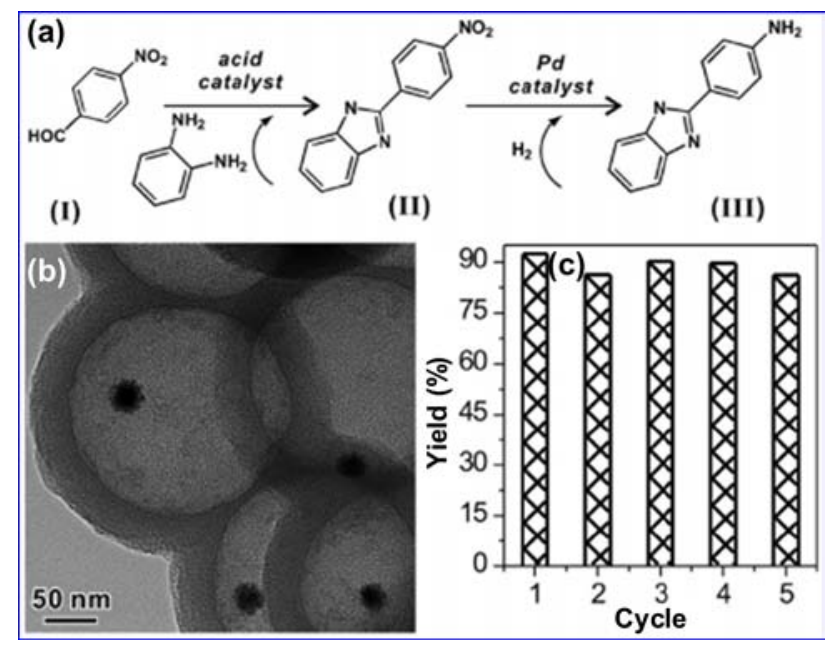

Fig. 8. (a) Illustration of the multistep reaction sequence involving an acid catalysis and subsequent catalytic hydrogenation for the synthesis of 2-(4-aminophenyl)-1H-benzimidazole. (b) TEM image of Pd/Au@ [Na]-HMAS. (c) Synthesis yield of 2-(4-aminophenyl)-1H-benzimidazole in the five successive reactions with Pd/Au@[Na]-HMAS [102]. sites, must be spatially isolated so that they can coexist in one catalyst $[104,105]$. Several nanostructured silica materials have been employed as the support $[106,107]$ for the site-isolated immobilization of acidic and basic catalytic species [108]. Many research groups have tried to improve the catalytic performance by controlling the morphology and structure of the catalysts $[109,110]$. Core-shell nanostructures are promising candidates as nanoreactors for such tandem reactions due to the spatially separated core and shell that can support the different active sites.

Yang's group [97] demonstrated a fabrication of a tandem catalyst using yolk-shell nanoparticles (YSNs) with controllable chemical composition, spatial separation of functional groups, and tunable porosity of the shell. The tandem catalyst (YS- $\left.\mathrm{NH}_{2} @ \mathrm{SO}_{3} \mathrm{H}\right)$ with a basic core $\left(-\mathrm{NH}_{2}\right)$ and an acidic shell $\left(-\mathrm{SO}_{3} \mathrm{H}\right)$ was synthesized with the organosilane-assisted selective etching method. The catalytic efficiency of these YSNs as nanoreactors for catalyzing the deacetalization-Henry tandem reaction was demonstrated (Fig. 9). The tandem reaction was efficiently catalyzed by this catalyst with nearly full conversion and selectivity [97]. This suggested that acid on the shell and base in the core were efficiently separated by the unique yolk-shell nanostructure without neutralization. The mixture of YS-NH $\mathrm{N}_{2} @$ ethanesilica and YS-silica@SO $3 \mathrm{H}$ can also catalyze the reaction with $55 \%$ conversion under the same reaction conditions. This synthesis method has been extended to synthesize various functionalized yolk-shell structures, thus providing a general approach for the fabrication of multifunctional nanoreactors.

Alternatively, a bifunctional core-shell catalyst with the acid sites in the inner core and the basic group in the outer shell was also prepared by Song's groups [111]. The acid and basic sites on the mesoporous silica nanospheres were spatially isolated. Using the one-pot deprotection-knoevenagel tandem reaction
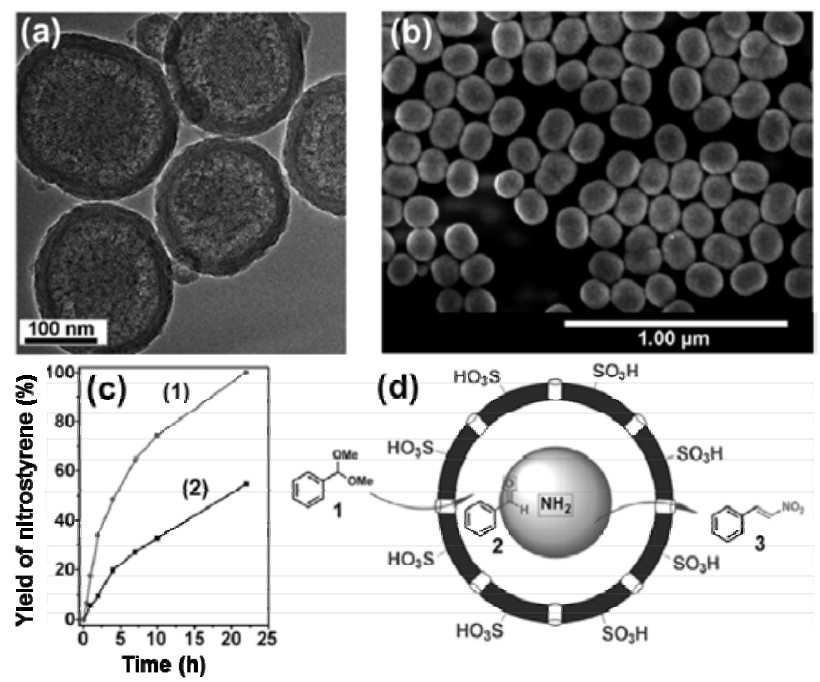

Fig. 9. Characterization of YSNs with basic cores and acidic shells (YS-NH $\mathrm{N}_{2} @ \mathrm{SO}_{3} \mathrm{H}$ ). (a) TEM image, (b) SEM image; (c) Catalytic performance of the YSN nanoreactor: The reaction profiles of YS- $\mathrm{NH}_{2} @ \mathrm{SO}_{3} \mathrm{H}$ (1), and the mixture of YS- $\mathrm{NH}_{2} @$ ethanesilica and YS-silica@SO ${ }_{3} \mathrm{H}$ for the Deacetalization-Henry cascade reaction (2); (d) Schematic illustration of the cascade reaction in a YS- $\mathrm{NH}_{2} @ \mathrm{SO}_{3} \mathrm{H}$ nanoreactor [97]. 
as the model reaction, the rationally designed spatial ordering of acid sites and basic sites led to excellent activity and selectivity in two types of reaction sequences, with nearly full conversion of the starting reactants and nearly $100 \%$ yield of the target products.

To take one step further, the fabrication of core-shell tandem nanocatalysts with a delicate structure, which combine two different types of catalytically active sites with a magnetic functionality as a multifunctional nanosystem for one-pot cascade reaction sequences is still a great challenge. Recently, Song and co-workers [112] presented a hierarchical core-shell satellite structured composite system $\mathrm{Fe}_{3} \mathrm{O}_{4} @ \mathrm{MS}-\mathrm{NH}_{2} @ \mathrm{Pd}$. This was composed of Pd nanoparticles well dispersed on amino group functionalized mesoporous silica (MS- $\mathrm{NH}_{2}$ ) nanospheres, and superparamagnetic $\mathrm{Fe}_{3} \mathrm{O}_{4}$ nanoparticles were scattered inside the silica sphere. The composite combined the catalytic properties of the amino groups and Pd nanoparticles with the paramagnetic properties of magnetite. Hyeon's group [113] also reported a one-pot synthesis of a magnetically recyclable mesoporous silica catalyst for acid-base tandem reactions. The catalyst showed excellent performance with very high yield and selectivity for the conversion of benzaldehyde dimethyl acetal to 1-nitro-2-phenylethylene via benzaldehyde using tandem acid-catalyzed deacetalization and base-catalyzed Henry reaction. They also present results of the effect of pore size on the catalytic activity of the mesoporous materials. The comparison studies revealed that the larger pore-sized materials exhibited a higher catalytic activity than the smaller pore-sized ones [113].

This integrated nanosystem was an efficient magnetically recyclable multifunctional (i.e., noble metal-base, acid-base, zeolite-metal) catalyst and showed excellent catalytic activity, selectivity and stability under mild conditions for facile one-pot multistep cascade reaction sequences.

\section{Summary and perspective}

The focus was on the recent progress of the synthesis and catalytic application of multifunctional nanocatalysts with a core-shell configuration. The engineering of a core-shell nanocatalyst with the appropriate components, spatial arrangement, and interface chemistry significantly enhances the stability, activity, and recyclability. The incorporated functionalities range from a facile separation ability, using magnetic particles embedding or post-modification, to the manipulation of multiple catalytically active phases in one compact catalyst to give finally a multifunctional nanostructured catalyst system. In most cases, porous silica and carbon are used as the shell material due to their useful chemistry, tunable structure, easy functionalization, and good stability. In addition, polymeric shells are also interesting in this field because they can be synthesized with a broad range of incorporated functionalities, such as sulfonic acid groups for acid catalysis.

For designing a core-shell catalyst with multi-component active sites, the immobilization of active species on one catalyst is the necessary prerequisite to isolate them and prevent their interference with each other. In addition to the spatial isolation of active sites, a higher goal in catalyst design is to rationally arrange the location of the active sites so that the order of the reaction sequence, order of the active site location and direction of mass transport on the catalyst surface can be optimized. The concept to use programmed core-shell catalysts with multiple components and adjustable functionalities is likely to fulfill various functions, especially for magnetically separable tandem catalysts with a more complex structure design. High quality (e.g., well-defined structures, controlled size, and tunable surface property) core-shell nanohybrids are more desirable in many cases of catalysis for both fundamental research and practical applications. Although the present preparation procedure and cost of these nanostructures may limit their utilization in industry, new and improved core-shell nanostructures for catalytic application are being discovered with the development of the new synthesis methodologies. We believe the novel nanostructures will have a particularly large impact on the sophisticated design of high performance nanocatalysts for sustainable development.

\section{An-Hui Lu}

State Key Laboratory of Fine Chemicals, School of Chemical Engineering, Dalian University of Technology, Dalian 116024, Liaoning, China

Tel/Fax: +86-411-84986112

E-mail: anhuilu@dlut.edu.cn

Received 15 February 2015

Published 20 May 2015

DOI: 10.1016/S1872-2067(14)60298-9

\section{References}

[1] Zhang Q, Lee I, Joo J B, Zaera F, Yin Y D. Acc Chem Res, 2013, 46: 1816

[2] Lee I, Albiter M A, Zhang Q, Ge J P, Yin Y D, Zaera F. Phys Chem Chem Phys, 2011, 13: 2449

[3] Goesmann H, Feldmann C. Angew Chem Int Ed, 2010,49: 1362

[4] Mitsudome T, Takahashi Y, Ichikawa S, Mizugaki T, Jitsukawa K, Kaneda K. Angew Chem Int Ed, 2013, 52: 1481

[5] Das S, Asefa T. Top Catal, 2012, 55: 587

[6] Yao T J, Cui T Y, Fang X, Cui F, Wu J. Nanoscale, 2013, 5: 5896

[7] Yang H Q, Li G, Ma Z C.J Mater Chem, 2012, 22: 6639

[8] Yao T J, Cui T Y, Wu J, Chen Q Z, Yin X J, Cui F, Sun K N. Carbon, 2012, 50: 2287

[9] Jiang K, Zhang H X, Yang Y Y, Mothes R, Lang H, Cai W B. Chem Commun, 2011, 47: 11924

[10] Li Y, Kim Y J, Kim A Y, Lee K, Jung M H, Hur N H, Park K H, Seo W S. Chem Mater, 2011, 23: 5398

[11] Ji J H, Zeng P H, Ji S F, Yang W, Liu H F, Li Y Y. Catal Today, 2010, 158: 305

[12] Liu J, Qiao S Z, Hartono S B, Lu G Q M. Angew Chem Int Ed, 2010, 49: 4981

[13] Chen Z, Cui Z M, Niu F, Jiang L, Song W G. Chem Commun, 2010, 46: 6524

[14] Mitsudome T, Kaneda K. ChemCatChem, 2013, 5: 1681

[15] Joo S H, Park J Y, Tsung C K, Yamada Y, Yang P D, Somorjai G A. Nat Mater, 2009, 8: 126

[16] Schärtl W. Nanoscale, 2010, 2: 829

[17] Caruso F. Adv Mater, 2001, 13: 11 


\section{Graphical Abstract}

Chin. J. Catal., 2015, 36: 683-691 doi: 10.1016/S1872-2067(14)60298-9

\section{Recent progress on core-shell nanocatalysts}

Qiang Sun, Xiang-Qian Zhang, Yang Wang, An-Hui Lu* Dalian University of Technology

Recent development of hollow core-shell nanocatalysts, magnetic nanocatalysts and tandem catalysts with core-shell nanostructures for improving catalytic efficiency, stability and recyclability was reviewed.

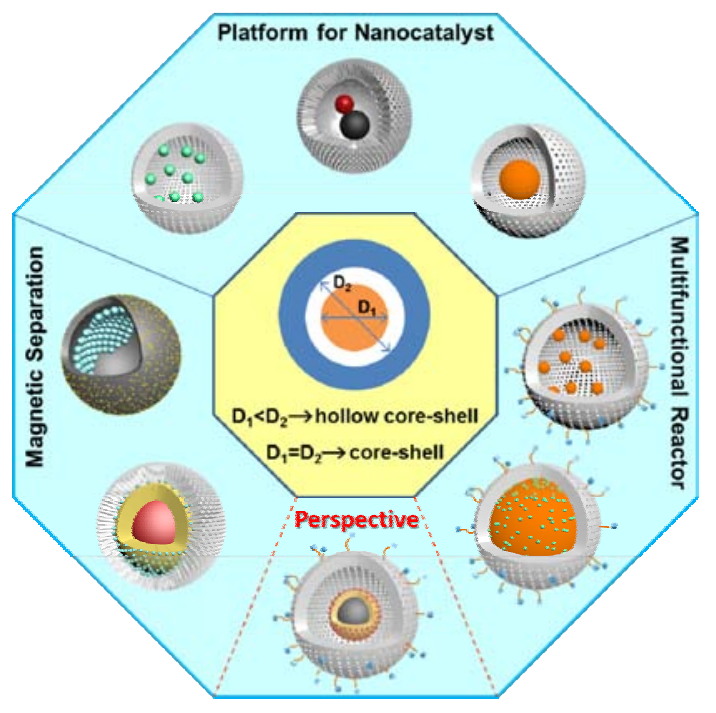

[18] Reiss P, Protière M, Li L. Small, 2009, 5: 154

[19] Kamata K, Lu Y, Xia Y N. J Am Chem Soc, 2003, 125: 2384

[20] Lee I, Joo J B, Yin Y D, Zaera F. Angew Chem Int Ed, 2011, 50 10208

[21] Dillon R J, Joo J B, Zaera F, Yin Y D, Bardeen C J. Phys Chem Chem Phys, 2013, 15: 1488

[22] Sreekumaran Nair A, Pradeep T, MacLaren I. J Mater Chem, 2004, 14: 857

[23] Guan B Y, Wang T, Zeng S J, Wang X, An D, Wang D M, Cao Y, Ma D X, Liu Y L, Huo Q S. Nano Res, 2014, 7: 246

[24] Güttel R, Paul M, Schüth F. Catal Sci Technol, 2011, 1: 65

[25] Arnal P M, Comotti M, Schüth F. Angew Chem Int Ed, 2006, 45: 8224

[26] Chen C, Fang X L, Wu B H, Huang L J, Zheng N F. ChemCatChem, 2012, 4: 1578

[27] Liang X L, Li J, Joo J B, Gutiérrez A, Tillekaratne A, Lee I, Yin Y D, Zaera F. Angew Chem Int Ed, 2012, 51: 8034

[28] Lee J, Park J C, Song H. Adv Mater, 2008, 20: 1523

[29] Lee J, Park J C, Bang J U, Song H. Chem Mater, 2008, 20: 5839

[30] Park J C, Bang J U, Lee J, Ko C H, Song H. J Mater Chem, 2010, 20: 1239

[31] Liu C M, Guo L, Wang R M, Deng Y, Xu H B, Yang S H. Chem Commun, 2004: 2726

[32] Zhang Q, Wang W, Goebl J, Yin Y. Nano Today, 2009, 4: 494

[33] Güttel R, Paul M, Schüth F. Chem Commun, 2010, 46: 895

[34] Güttel R, Paul M, Galeano C, Schüth F. J Catal, 2012, 289: 100

[35] Galeano C, Güttel R, Paul M, Arnal P, Lu A H, Schüth F. Chem Eur J, 2011, 17: 8434

[36] Huang X Q, Guo C Y, Zuo J Q, Zheng N F, Stucky G D. Small, 2009, 5: 361

[37] Chen Z, Cui Z M, Niu F, Jiang L, Song W G. Chem Commun, 2010, 46: 6524

[38] Chen Z, Cui Z M, Li P, Cao C Y, Hong Y L, Wu Z Y, Song W G.J Phys Chem C, 2012, 116: 14986

[39] Tan L F, Chen D, Liu H Y, Tang F Q. Adv Mater, 2010, 22: 4885

[40] Zhang X M, Zhao Y P, Xu S T, Yang Y, Liu J, Wei Y X, Yang Q H. Nat Commun, 2014, 5: 3170

[41] Zhang X M, Zhao Y P, Yang Q H. J Catal, 2014, 320: 180

[42] Deng D H, Yu L, Chen X Q, Wang G X, Jin L, Pan X L, Deng J, Sun G Q,
Bao X H. Angew Chem Int Ed, 2013, 52: 371

[43] Poliakoff M, Fitzpatrick J M, Farren T R, Anastas P T. Science, 2002, 297: 807

[44] Liu J, Yang H Q, Kleitz F, Chen Z G, Yang T Y, Strounina E, Lu G Q M, Qiao S Z. Adv Funct Mater, 2012, 22: 591

[45] Sheldon R A, van Bekkum H. Fine Chemicals through Heterogeneous Catalysis. Weinheim: Wiley-VCH, 2001

[46] Jacinto M J, Santos O H C F, Jardim R F, Landers R, Rossi L M. Appl Catal A, 2009, 360: 177

[47] Lu A H, Schmidt W, Matoussevitch N, Bönnemann H, Spliethoff B, Tesche B, Bill E, Kiefer W, Schüth F. Angew Chem Int Ed, 2004, 43: 4303

[48] Tsang S C, Caps V, Parakevas I, Chadwick D, Thompsett D. Angew Chem Int Ed, 2004, 43: 5645

[49] Lapresta-Fernández A, Doussineau T, Moro A J, Dutz S, Steiniger F, Mohr G J. Anal Chim Acta, 2011, 707: 164

[50] Zhang X L, Niu H Y, Li W H, Shi Y L, Cai Y Q. Chem Commun, 2011, 47: 4454

[51] Cheng G, Zhang J L, Liu Y L, Sun D H, Ni J Z. Chem Commun, 2011, 47: 5732

[52] Salgueiriño-Maceira V, Correa-Duarte M A, Spasova M, Liz-Marzán L M, Farle M. Adv Funct Mater, 2006, 16: 509

[53] Guo W C, Wang Q, Wang G, Yang M, Dong W J, Yu J. Chem Asian J, 2013, 8: 1160

[54] Shylesh S, Schünemann V, Thiel W R. Angew Chem Int Ed, 2010, 49: 3428

[55] Aschwanden L, Panella B, Rossbach P, Keller B, Baiker A. ChemCatChem, 2009, 1: 111

[56] Salgueiriño-Maceira V, Correa-Duarte M A, Farle M, López-Quintela A, Sieradzki K, Diaz R. Chem Mater, 2006, 18: 2701

[57] Bedford R B, Betham M, Bruce D W, Davis S A, Frost R M, Hird M. Chem Commun, 2006: 1398

[58] Li J, Liang X L, Joo J B, Lee I, Yin Y D, Zaera F. J Phys Chem C, 2013, 117: 20043

[59] Goebl J, Yin Y D. ChemCatChem, 2013, 5: 1287

[60] Liang X L, Li J, Joo J B, Gutiérrez A, Tillekaratne A, Lee I, Yin Y D, Zaera F. Angew Chem Int Ed, 2012, 51: 8034

[61] Ye M M, Zhang Q, Hu Y X, Ge J P, Lu Z D, He L, Chen Z L, Yin Y D. Chem Eur J, 2010, 16: 6243 
[62] Ge J P, Hu Y X, Biasini M, Beyermann W P, Yin Y D. Angew Chem Int Ed, 2007, 46: 4342

[63] Ge J P, Zhang Q, Zhang T R, Yin Y D. Angew Chem Int Ed, 2008, 47: 8924

[64] Feyen M, Weidenthaler C, Güttel R, Schlichte K, Holle U, Lu A H, Schüth F. Chem Eur J, 2011, 17: 598

[65] Deng Y H, Cai Y, Sun Z K, Liu J, Liu C, Wei J, Li W, Liu C, Wang Y, Zhao D Y.J Am Chem Soc, 2010, 132: 8466

[66] Kim J, Kim H S, Lee N, Kim T, Kim H, Yu T, Song I C, Moon W K, Hyeon T. Angew Chem Int Ed, 2008, 47: 8438

[67] Yeo K M, Shin J, Lee I S. Chem Commun, 2010, 46: 64

[68] Barmatova M V, Ivanchikova I D, Kholdeeva O A, Shmakov A N, Zaikovskii V I, Meĺgunov M S. J Mater Chem, 2009, 19: 7332

[69] Wu Z J, Sun C X, Chai Y, Zhang M H. RSC Adv, 2011, 1: 1179

[70] Feyen M, Weidenthaler C, Schüth F, Lu A H. J Am Chem Soc, 2010, 132: 6791

[71] Lu A H, Nitz J J, Comotti M, Weidenthaler C, Schlichte K, Lehmann C W, Terasaki O, Schüth F. J Am Chem Soc, 2010, 132: 14152

[72] Sun Q, Guo C Z, Wang G H, Li W C, Bongard H J, Lu A H. Chem Eur J, 2013, 19: 6217

[73] Feyen M, Weidenthaler C, Schüth F, Lu A H. Chem Mater, 2010, 22: 2955

[74] Polshettiwar V, Luque R, Fihri A, Zhu H B, Bouhrara M, Basset J M. Chem Rev, 2011, 111: 3036

[75] Jia C J, Schüth F. Phys Chem Chem Phys, 2011, 13: 2457

[76] Noda H, Motokura K, Miyaji A, Baba T. Angew Chem Int Ed, 2012 , 51: 8017

[77] Fraile J M, García N, Herrerías C I, Martín M, Mayoral J A. ACS Catal, 2012, 2: 56

[78] Sharma K K, Biradar A V, Das S, Asefa T. Eur J Inorg Chem, 2011, (21): 3174

[79] Climent M J, Corma A, Iborra S. Chem Rev, 2011, 111: 1072

[80] Albrecht $€$, Jiang H, Jörgensen K A. Angew Chem Int Ed, 2011, 50 : 8492

[81] Shiju N R, Alberts A H, Khalid S, Brown D R, Rothenberg G. Angew Chem Int Ed, 2011, 50: 9615

[82] Huang Y L, Xu S, Lin V S Y. Angew Chem Int Ed, 2011, 50: 661

[83] Zeidan R K, Hwang S J, Davis M E. Angew Chem Int Ed, 2006, 45: 6332

[84] Shylesh S, Wagener A, Seifert A, Ernst S, Thiel W R. Angew Chem Int Ed, 2010, 49: 184

[85] Peng H G, Xu L, Zhang L Y, Zhang K, Liu Y M, Wu H H, Wu P.J Mater Chem, 2012, 22: 14219

[86] Ren N, Yang Y H, Zhang Y H, Wang Q R, Tang Y. J Catal, 2007, 246: 215

[87] Tan L F, Chen D, Liu H Y, Tang F Q. Adv Mater, 2010, 22: 4885
[88] Salgueiriño-Maceira V, Correa-Duarte M A. Adv Mater, 2007, 19: 4131

[89] Chaudhuri R G, Paria S. Chem Rev, 2012, 112: 2373

[90] Wei S Y, Wang Q, Zhu J H, Sun L Y, Lin H F, Guo Z H. Nanoscale, 2011, 3: 4474

[91] Liu J, Qiao S Z, Chen J S, Lou X W, Xing X R, Lu G Q M. Chem Commun, 2011, 47: 12578

[92] Ren N, Yang Y H, Shen J, Zhang Y H, Xu H L, Gao Z, Tang Y.J Catal, 2007, 251: 182

[93] Yang H Q, Chong Y Z, Li X K, Ge H, Fan W B, Wang J G. J Mater Chem, 2012, 22: 9069

[94] Shokouhimehr M, Piao Y, Kim J, Jang Y, Hyeon T. Angew Chem Int Ed, 2007, 46: 7039

[95] Dong H J, Brennan J D. Chem Commun, 2011, 47: 1207

[96] Zhang Q, Lee I, Ge J P, Zaera F, Yin Y D. Adv Funct Mater, 2010, 20 : 2201

[97] Yang Y, Liu X, Li X B, Zhao J, Bai S Y, Liu J, Yang Q H. Angew Chem Int Ed, 2012, 51: 9164

[98] Pinkaew K, Yang G H, Vitidsant T, Jin Y Z, Zeng C Y, Yoneyama Y, Tsubaki N. Fuel, 2013, 111: 727

[99] Li P, Cao C Y, Liu H, Yu Y, Song W G. J Mater Chem A, 2013, 1: 12804

[100] Peng H G, Xu L, Zhang L Y, Zhang K, Liu Y M, Wu H H, Wu P. J Mater Chem, 2012, 22: 14219

[101] Peng H G, Xu L, Wu H H, Zhang K, Wu P. Chem Commun, 2013, 49: 2709

[102] Fang X L, Liu Z H, Hsieh M F, Chen M, Liu P X, Chen C, Zheng N F. ACS Nano, 2012, 6: 4434

[103] Bellina F, Calandri C, Cauteruccio S, Rossi R. Tetrahedron. 2007, 63: 1970

[104] Voit B. Angew Chem Int Ed, 2006, 45: 4238

[105] Thomas J M, Raja R, Lewis D W. Angew Chem Int Ed, 2005, 44: 6456

[106] Kesanli B, Lin W B. Chem Commun, 2004, (20): 2284

[107] Perego C, Millini R. Chem Soc Rev, 2013, 42: 3956

[108] Margelefsky E L, Zeidan R K, Davis M E. Chem Soc Rev, 2008, 37: 1118

[109] Zhang L, Guo Y N, Peng J A, Liu X, Yuan P, Yang Q H, Li C. Chem Commun, 2011, 47: 4087

[110] Sharma K K, Anan A, Buckley R P, Ouellette W, Asefa T. J Am Chem Soc, 2008, 130: 218

[111] Li P, Cao C Y, Chen Z, Liu H, Yu Y, Song W G. Chem Commun, 2012, 48: 10541

[112] Li P, Yu Y, Liu H, Cao C Y, Song W G. Nanoscale, 2014, 6: 442

[113] Jun S W, Shokouhimehr M, Lee D J, Jang Y, Park J, Hyeon T. Chem Commun, 2013, 49: 7821 